Original Research Paper

\title{
Finite-Element Numerical Simulation of the Bending Performance of Post-Tensioned Structural Glass Beams with Adhesively Bonded CFRP Tendons
}

\author{
${ }^{1}$ Chiara Bedon and ${ }^{2,3}$ Christian Louter \\ ${ }^{1}$ Department of Engineering and Architecture (DIA), University of Trieste, Trieste, Italy \\ ${ }^{2}$ Department of Architectural Engineering and Technology $(A E+T)$, Faculty of Architecture and the Built \\ Environment $(A+B E)$, Delft University of Technology (TU Delft), The Netherlands \\ ${ }^{3}$ Steel Structures Laboratory (ICOM), Civil Engineering Institute (IIC), School of Architecture, \\ Civil and Environmental Engineering (ENAC), École Polytechnique Fédérale de Lausanne (EPFL), Switzerland
}

\begin{abstract}
Article history
Received: 15-07-2016

Revised: 08-08-2016

Accepted: 09-08-2016

Corresponding Author:

Chiara Bedon

University of Trieste, Italy

Email: bedon@dicar.units.it
\end{abstract}

\begin{abstract}
In this paper, a Finite-Element (FE) numerical investigation is carried out on laminated glass beams with Carbon Fibre Reinforced Polymer (CFRP) adhesively bonded post-tensioning tendons. Taking advantage of past four-point bending experimental test results available in literature, a refined full 3D FE numerical model is calibrated and validated. A key role is given to a multitude of aspects, including the implementation of damage models for materials as well as the appropriate mechanical interaction between the beam components, in order to properly reproduce the expected effects of post-tensioning as well as the overall bending behavior for the examined structural typology.
\end{abstract}

Keywords: Structural Glass, Laminated Glass, Post-Tensioned Glass, Carbon Fibre Reinforced Polymer (CFRP) Tendon, Finite-Element (FE) Numerical Modeling

\section{Introduction}

This paper adds an FE-analysis to the experimental findings on post-tensioned glass beams presented in (Louter et al., 2014a). These posttensioned glass beams consist of a laminated glass web and Carbon Fibre Reinforced Polymer (CFRP) post-tensioning tendons that are adhesively bonded to the tensile edge of the glass beam.

The concept of post-tensioned glass beams is investigated in a modest number of research projects (Bos et al., 2004; Jordão et al., 2014; Louter et al., 2014b; Cupać and Louter, 2015; Engelmann and Weller, 2016) and has also been applied in practice (Schober et al., 2004). A comprehensive state-of-the-art overview is provided in (Martens et al., 2015a; 2015b). Since glass is relatively weak in tension but strong in compression, the purpose of adding post-tensioning tendons to a glass beam is firstly to apply a beneficial compressive prestress. This compressive pre-stress will augment the initial fracture strength of the glass beam. By placing the post-tensioning tendon at a certain distance from the neutral beam axis a positive uplift is additionally provided to the beam thereby further enhancing the initial fracture strength of the glass beam. Secondly, the post-tensioning tendons provide safe post-fracture performance. Upon fracture of the glass the tendons will bridge the crack(s) and transfer the tensile force over the cracks. This generates an efficient internal moment capacity between the tendon and the compressed (top) part of the glass beam, thereby providing the beam significant post-fracture load-carrying performance.

Typically, steel tendons, that are either mechanically anchored or adhesively bonded to the glass beam are applied (Louter et al., 2014a; 2014b). However, the current contribution focuses on CFRP tendons to enhance the pre-fracture and post-fractureperformance of glass beams. As such, it shows similarities with other applications in structures, including reinforced concrete (i.e. Khalifa and Nanni, 2002; Wu et al., 2005), steel (i.e. Colombi and Poggi, 2006; Seleem et al., 2010), timber (i.e. Johnsson et al., 2006; Nadira et al., 2016) and even glass (i.e. Correia et al., 2011; Speranzini and Agnetti, 2015). Benefit of the CFRP tendons is the enhanced tensile strength compared to regular steel tendons and thus a more efficient use of material.

The concept of post-tensioned glass beams has, to a substantial extent, been experimentally investigated in the aforementioned research projects. However, attempts to rationally simulate the structural response of such post-tensioned glass beams through advanced Finite- 
Element (FE) numerical models are currently limited (see for example Bedon and Louter, 2016). Therefore, the current paper focuses on the FE investigation of previously tested glass beams with adhesively bonded CFRP post-tensioning tendons. A short recapitulation of the experimental results is first given in the following section. Subsequently, the FE analysis using refined 3D model is presented and critically discussed.

\section{Recapitulation of Experimental Test Results}

In order to assess the structural performance of CFRP-reinforced, post-tensioned laminated glass beams, three bending experiments were carried out. The experiments were performed at École Polytechnique Fédérale de Lausanne (EPFL) in Lausanne, Switzerland and have been accordingly published in (Débonnaire, 2013) and (Louter et al., 2014a).

\section{Specimens}

The post-tensioned glass beam specimens (three in total), as illustrated in Fig. 1, were made of a rectangular laminated glass web and a rectangular, pre-stressed CFRP tendon positioned at the bottom edge. The typical laminated glass beam, with nominal cross-sectional dimensions of $125 \mathrm{~mm}$ by $25.04 \mathrm{~mm}$, was obtained by laminating three annealed glass plies $(6 \mathrm{~mm}$ and $10 \mathrm{~mm}$ the thicknesses for the two external and the middle glass layers respectively) with two intermediate SentryGlas ${ }^{\circledR}$ (SG) interlayer foils with a nominal thickness of $1.52 \mathrm{~mm}$ each.

After lamination, the edges of the glass beam have been polished to ensure a smooth surface for bonding the CFRP tendon at a later stage. Lamination and polishing was done by a professional processor.

For the CFRP tendon, a solid section was used, with nominal section dimensions of $2 \times 25 \mathrm{~mm}$, spanning over the total length of the laminated glass beam. The CFRP solid section consisted of standard carbon fibers (Torayca T700 (Torayca, 2008) or equivalent) and a surrounding matrix of epoxy resin. The nominal mechanical properties are provided in Table 1, as given by the producer. The mechanical interaction between the laminated glass beam and the pre-tensioned CFRP tendon was finally provided by a layer of twocomponent epoxy adhesive, 3M DP490 (3M ScotchWeld $\left.{ }^{\mathrm{TM}}, 1996\right)$, with a nominal thickness of $0.1 \mathrm{~mm}$.

\section{Post-Tensioning Method}

The laminated glass beams were post-tensioned using a specially devised post-tensioning rig. This rig consisted of a steel U-section $(70 \times 45 \times 5 \mathrm{~mm})$ in which the CFRP tendon was pre-tensioned, see Fig. 2 and 3. To grip the CFRP tendon, steel blocks (at side A, see Fig. 3) and a steel strip (at side B, see Fig. 3) were adhesively bonded to the CFRP tendon using the 3M DP490 twocomponent epoxy adhesive.

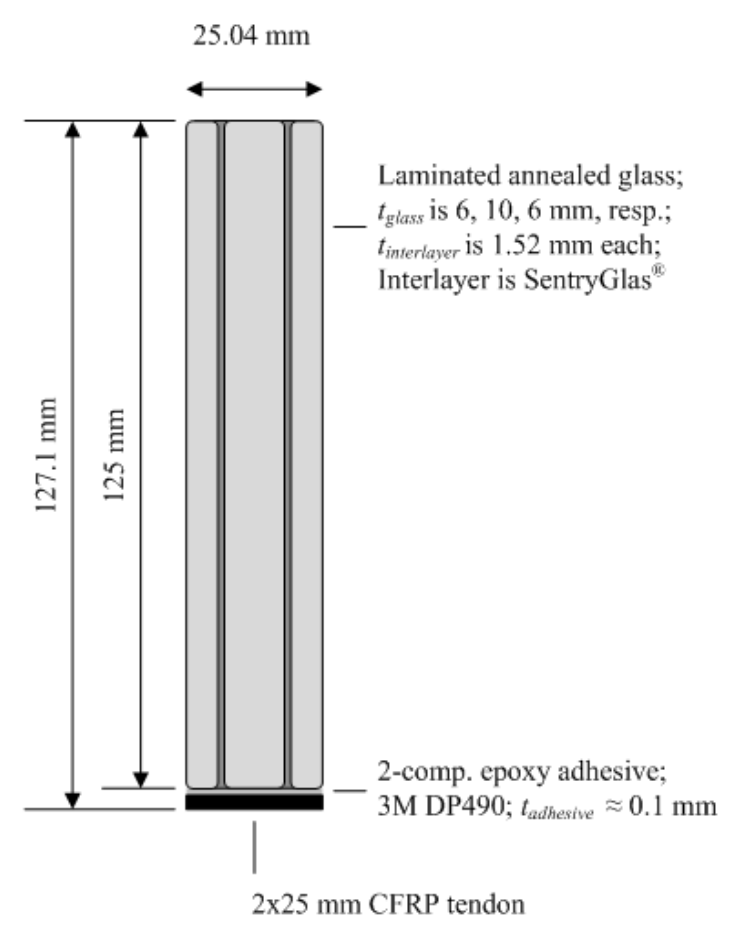

Fig. 1. Transversal cross-section of the laminated glass beam specimens with adhesively bonded CFRP posttensioning tendon, nominal dimensions

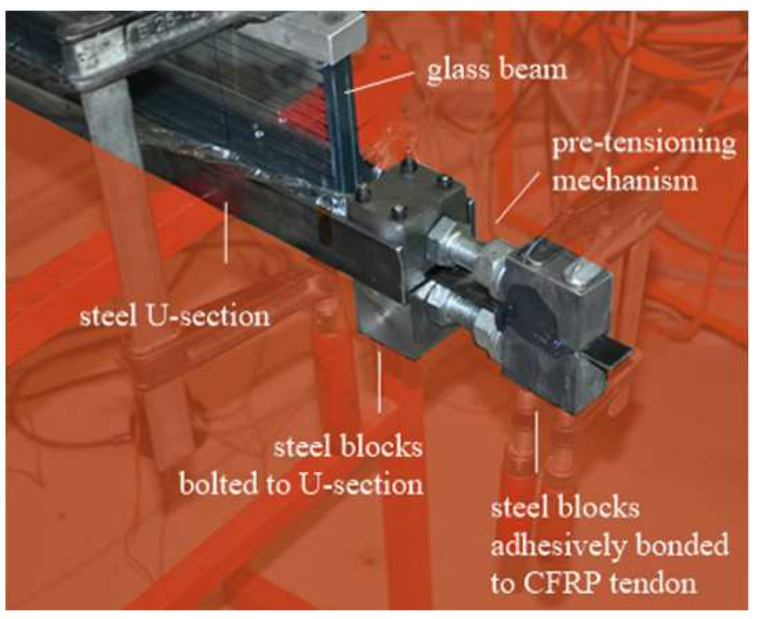

Fig. 2. Photograph of the post-tensioning rig (side A)

At side B, see Fig. 2, the steel strip was subsequently bolted to the U-section to anchor that end of the CFRP tendon. At side A, see Fig. 2, a pre-tensioning mechanism was devised by means of bolts, nuts, washers and additional steel contrast blocks that are bolted to the U-section. By rotating the nuts, the distance $a$ between the two sets of steel blocks is enlarged thereby tensioning the CFRP tendon. While tensioning the CFRP tendon to the desired pre-load, i.e. $P_{0} \approx 13.6 \mathrm{kN}$ in this study, the tensile force in the CFRP tendon was monitored by means of strain gauge measurements. 


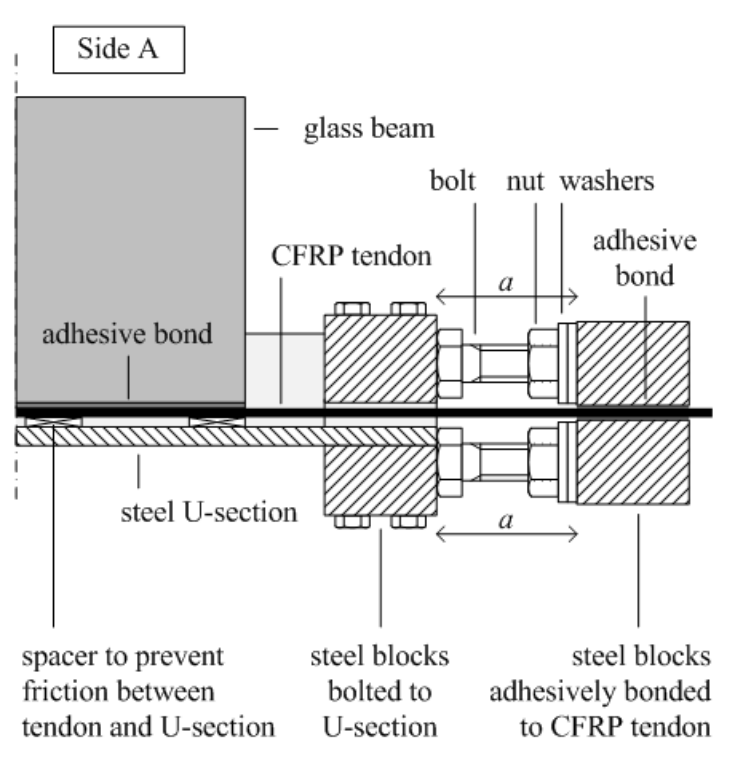

(a)

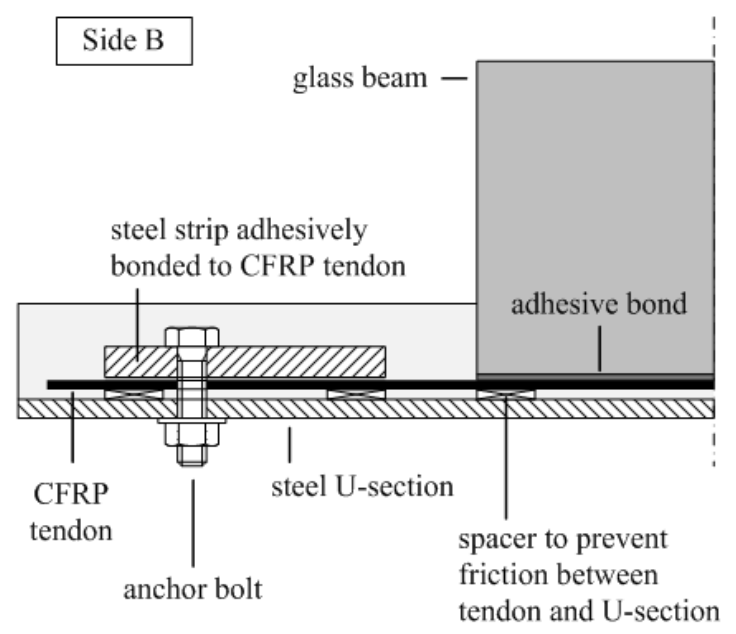

(b)

Fig. 3. Schematic representation of the post-tensioning rig, with details of (a) side A and (b) side B respectively longitudinal cross-section)

Table 1. Mechanical properties of the CFRP tendon, in accordance with (Torayca, 2008)

\begin{tabular}{llr}
\hline Property & Unit & Nominal value \\
\hline Density & $\mathrm{kg} / \mathrm{m}^{3}$ & 1600.0 \\
Tensile modulus & $\mathrm{GPa}$ & 135.0 \\
Tensile strength & $\mathrm{MPa}$ & 2550.0 \\
Compressive strength & $\mathrm{MPa}$ & 1600.0 \\
Elongation at fracture & $\%$ & 1.7 \\
\hline
\end{tabular}

These strain gauges were bonded to the CFRP tendon at the center of the beam (not indicated in Fig. 3). After tensioning the CFRP tendon, the epoxy adhesive was applied on the tendon. Subsequently the glass beam was positioned on the bond line and the adhesive was left to cure for at least three days. After this curing time, the tendon was released and the beam removed from the rig.

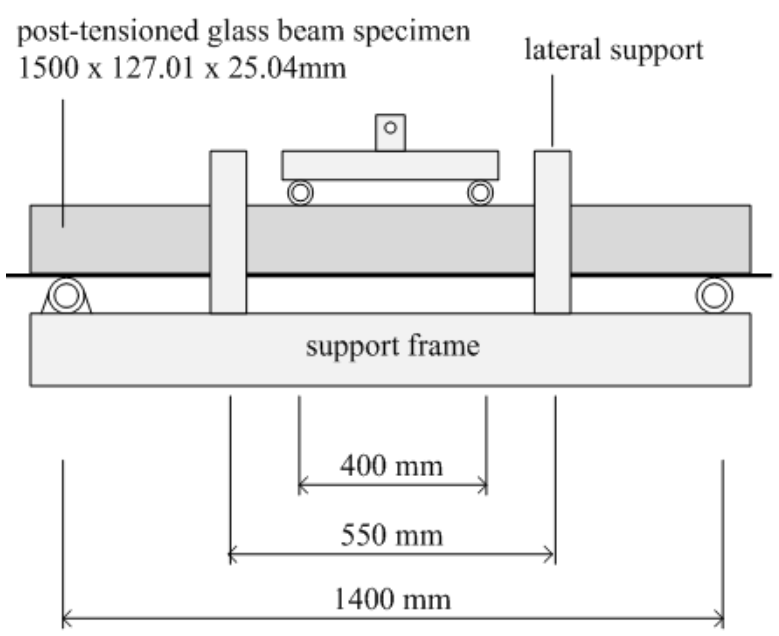

Fig. 4. Schematic representation of the four-point bending test setup (front view)

All the three experimental specimens were prepared in the same manner. The applied post-tensioning rig and procedure, as described above, is similar to the one used for steel tendons in preceding research (Débonnaire, 2013; Louter et al., 2014a; 2014b).

\section{Bending Test Setup}

After post-tensioning, the beams were tested in fourpoint bending using a support frame mounted on a Zwick $500 \mathrm{kN}$ universal tension-compression test machine. A schematic representation of the four-point bending test setup is provided in Fig. 4. The test setup is the same as described in (Louter et al., 2014a; 2014b).

The beams were supported at a distance of $1400 \mathrm{~mm}$ and loaded at a distance of $400 \mathrm{~mm}$. Lateral supports were positioned at a distance of $550 \mathrm{~mm}$. The beams were loaded at a displacement rate of $1 \mathrm{~mm} / \mathrm{min}$, which was augmented after initial glass fracture to $2 \mathrm{~mm} / \mathrm{min}$ and later $5 \mathrm{~mm} / \mathrm{min}$ to shorten test duration. The applied force and vertical displacement was recorded.

\section{Results}

The results of the bending tests are provided in Table 2. Additionally, Fig. 5 provides the load-displacement diagram obtained from the bending tests. Fig. 6 provides a photo sequence of an exemplary test.

The post-tensioned glass beams show an initial linear elastic response until initial glass fracture. This glass fracture occurred at an average load of $16.5 \mathrm{kN}$. This fracture load is about 1.9 times higher than identical beams without post-tensioning tendons, tested in previous research (Louter et al., 2014a). As elucidated in previous research this augmentation is to a certain extent explained by the beam's increased moment of inertia resulting from the additional adhesively bonded CFRP tendon. 


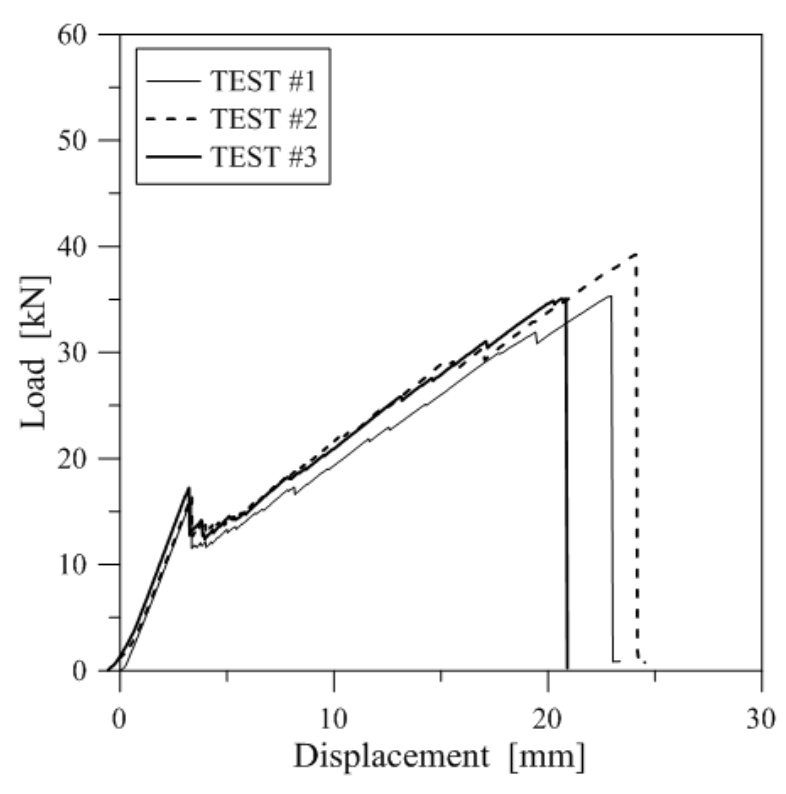

Fig. 5. Experimental load-displacement plots, as obtained from the four-point bending tests (Louter et al., 2014a)

Table 2. Results of the experiments (Louter et al., 2014a)

\begin{tabular}{lllll}
\hline Spec & $\begin{array}{l}P_{0} \\
{[\mathrm{kN}]}\end{array}$ & $\begin{array}{l}F_{\text {fracture }} \\
{[\mathrm{kN}]}\end{array}$ & $\begin{array}{l}F_{\text {post-fracture }} \\
{[\mathrm{kN}]}\end{array}$ & $R_{F}$ \\
\hline$\# 1$ & 13.8 & 15.9 & 35.3 & 2.22 \\
$\# 2$ & 13.1 & 16.3 & 39.2 & 2.40 \\
$\# 3$ & 14.0 & 17.2 & 35.1 & 2.03 \\
mean & 13.6 & 16.5 & 36.5 & 2.22 \\
\hline
\end{tabular}

$P_{0}=$ CFRP tendon pre-load;

$F_{\text {fracture }}=$ initial fracture load;

$F_{\text {post-fracture }}=$ maximum post-fracture load

$R_{F}=F_{\text {post-fracture }} / F_{\text {fracture }}=$ post-fracture reserve

But most importantly, the augmentation in initial fracture strength is largely resulting from the beneficial compressive pre-stress and uplift that is provided to the glass beam by means of the CFRP post-tensioning tendon.

Upon initial fracture, cracks occur in the glass that originate from the lower (tensile) beam edge and propagate upwards. The load-displacement diagram, see Fig. 3, shows a distinct drop in load. As loading is continued, in a displacement controlled manner, the load increases again and repetitive cracking of the glass occurs causing repetitive small disruptions in the loaddisplacement diagram. The slope of the loaddisplacement curve and thus the bending stiffness of the beam system, is reduced, see Fig. 5.

Gradually the cracks distributed over the length of the beam, see Fig. 6, until final failure is reached at an average load of $36.5 \mathrm{kN}$. Final failure was typically associated with explosive glass failure at the top part of the beam, tendon debonding and in some instances tendon failure.

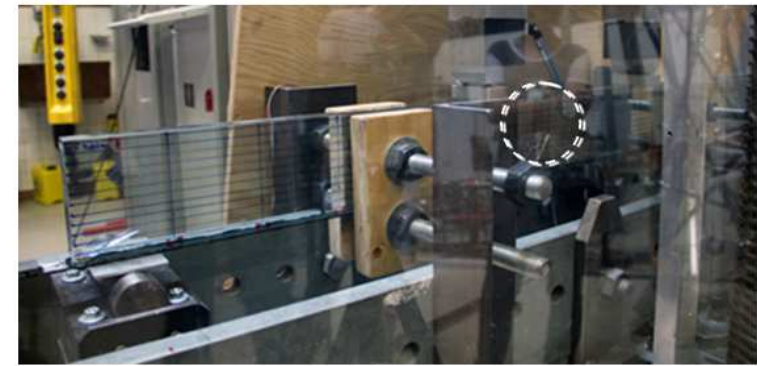

(a)

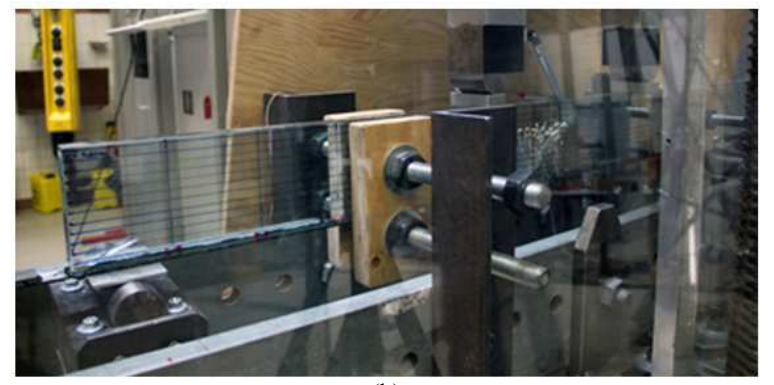

(b)

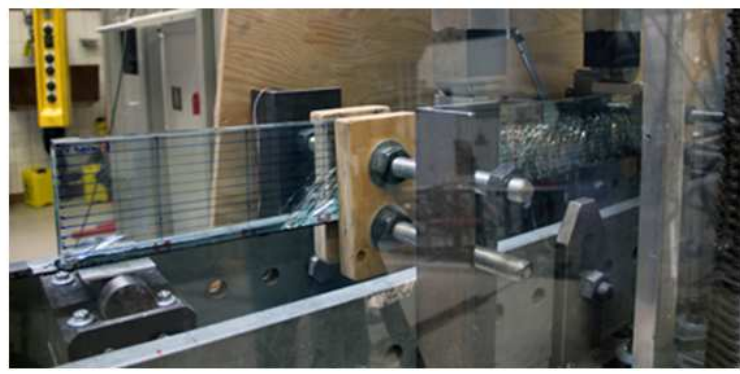

(c)

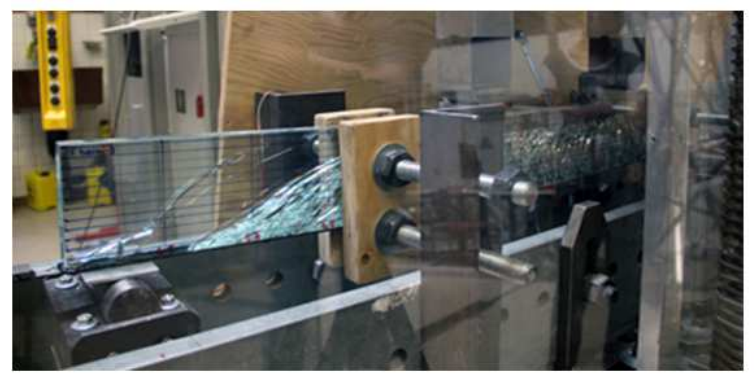

(d)

Fig. 6. Photo sequence of exemplary beam experiment on the post-tensioned glass beams. (a) Initial glass fracture; (b)(c) progressive cracking; (d) crack stage just before ultimate failure

All beams thus reached post-fracture loads in excess of the initial fracture load. In fact, ultimate failure load amounted to at least twice the initial fracture load as can be seen from the post-fracture reserve index provided in Table 2. The CFRP tendon has effectively enhanced the post-fracture performance of the glass beams by providing a post-fracture load-carrying mechanism. 


\section{Finite-Element Numerical Investigation}

Based on the available experimental test results, an extended investigation of the same design concept was carried out by means of geometrically and mechanically refined, full 3D solid Finite-Element numerical models implemented in the ABAQUS computer software (Simulia, 2012), see Fig. 7.

\section{Finite-Element Numerical Modeling Strategy}

The exploratory FE numerical investigation was carried out by giving careful attention to several aspects, including the mechanical calibration of materials (CFRP, glass, SG, adhesive), the post-tensioning phase and the mechanical interaction between the CFRPtendon and the laminated glass beam.

For this purpose, the typical FE model consisted of 3D solid elements for (i) the laminated glass beam, (ii) the CFRP tendon and (iii) the adhesive layer. C3D8R type elements available in the ABAQUS library were taken into account.

In terms of geometrical features, the nominal dimensions were considered for all the specimens components, as discussed in the experimental section. Several meshing approaches were then taken into account for each beam component, i.e. a free meshing technique for the laminated glass beam and a regular mesh pattern based on 8-node elements for the CFRP tendon and the adhesive layer. In the first case, the mesh reference size was modified in the range comprised between $1.5 \mathrm{~mm}$ and $30 \mathrm{~mm}$, in order to properly capture the tensile cracking phenomena in the specimen under in-plane bending, as well as to preserve the computational efficiency of the FE model. For the CFRP tendon and adhesive layers, the average mesh size was set equal to $10 \mathrm{~mm}$, including two solid elements in the thickness of each layer. As a result, the full FE assembly consisted of 140,000 solid elements and 60,000 degrees of freedom (DOFs).

\section{Materials}

The mechanical characterization of all the materials was based on past literature references as well as nominal reference values available in standards or technical data sheets provided by the producers.

For annealed glass, based on product standards (EN 572-2:2004), the nominal tensile strength $f_{i}=45 \mathrm{MPa}$ was taken into account. An homogeneous, linear elastic, isotropic material was used, with nominal values for the mechanical properties $\left(E_{\text {glass }}=70 \mathrm{GPa}, v_{\text {glass }}=0.23\right.$ ).

The possible brittle failure in tension was also taken into account, by means of the brittle cracking material model, including the brittle shear and brittle failure sub-options.

In the brittle cracking damage model, a Rankine failure criterion is used for the crack detection.

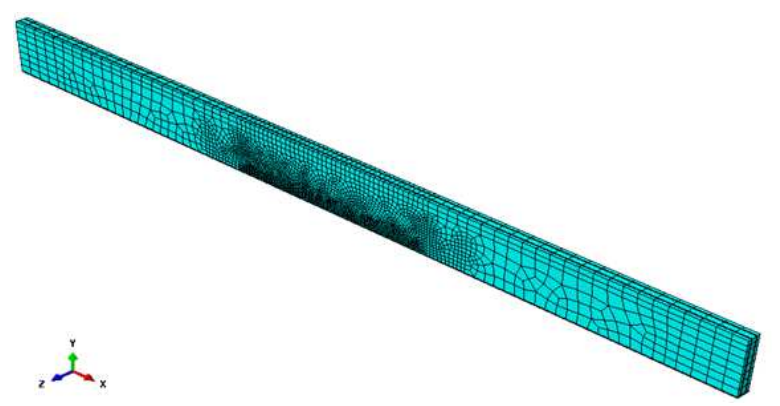

Fig. 7. Axonometry of the reference full 3D Finite-Element numerical model (ABAQUS (Simulia 2012))

Glass is consequently assumed to behave linear elastically until the maximum principal tensile stress exceeds the tensile strength $f_{t}$. Being a smeared model, the brittle cracking option does not track individual macro cracks, but the presence of cracks-having surface of propagation perpendicular to the direction of maximum principal stresses-is taken into account in the constitutive calculations performed at each material point, in the form of stress and stiffness degradation. Input parameters of this damage model are consequently the tensile strength of glass and its fracture energy.

In the current study, the input parameters for the damage model were derived from past literature contributions and recent $\mathrm{FE}$ analyses on similar composite glass systems, see for example (Bedon and Louter, 2014). The tensile strength was assumed equal to the nominal characteristic value $\left(f_{t}=45 \mathrm{MPa}\right)$, while for the fracture energy a reference value $G_{f}=3 \mathrm{~J} / \mathrm{m}^{2}$ was taken into account.

The post-cracked behavior was then described by means of the brittle shear and brittle failure sub-options. In accordance with the adopted shear retention model, the cracked shear modulus of glass $G_{c, g l a s s}$ is basically estimated as a fraction of the uncracked shear modulus $G_{\text {glass }}$ :

$G_{c, \text { glass }}=\beta\left(\varepsilon_{n n}^{c k}\right) \cdot G_{\text {glass }}$

With:

$0 \leq \beta\left(\varepsilon_{n n}^{c k}\right)=\left(1-\frac{\varepsilon_{n n}^{c k}}{\varepsilon_{\max }^{c k}}\right)^{p} \leq 1$

The shear retention factor, whose non-constant value depends on the crack opening strain $(\beta=0$ denoting complete loss of aggregate interlock and $\beta=1$ signifying the uncracked stage).

In Equations (1) and (2), $\varepsilon^{c k}{ }_{n n}$ and $\varepsilon^{c k}{ }_{\text {max }}$ represent the actual and ultimate crack opening strains respectively. The parameter $p$, based on earlier calibration (Bedon and Louter, 2014), was finally assumed equal to $p=5$. 
A further advantage of the adopted damage material model is given by the (possible) physical deletion of cracked elements from the mesh, via the brittle failure sub-option. In this regard, the ultimate displacement for the cracked glass elements was set equal to:

$$
u_{c k}=\frac{2 G_{f}}{f_{t}}
$$

Differing from (Bedon and Louter, 2014), in this research study the physical deletion of cracked elements from the mesh was fully disregarded, to avoid additional numerical instabilities in the post-cracked stage. The first occurrence of tensile damage and propagation of cracks was thus monitored in the beam in the form of damage energy distribution and evolution in the glass elements only.

Regarding the other FE model components, the material calibration was mainly derived from reference values available in literature from past experimental studies or FE investigations.

For the SG interlayer foils, despite their typical viscoelastic mechanical behavior (Santarsiero et al., 2016), an equivalent linear elastic material was used. In accordance with (Bedon and Louter, 2014), the elastic modulus $E_{S G}=120 \mathrm{MPa}$ was calibrated by taking into account the average test duration and the reference experimental temperature. The Poisson coefficient was set equal to $v_{S G}=0.49$.

In terms of CFRP tendon, a linear elastic material was taken into account. Based on (Torayca, 2008) and Table 1 , a modulus of elasticity $E_{C F R P}=135 \mathrm{GPa}$ was used, with $v_{C F R P}=0.3$ the Poisson's ratio. Due to the relatively high nominal tensile resistance of the composite tendon, compared to glass, the occurrence of any possible damage in the tendon alone was fully disregarded at this stage of the research study.

For the adhesive layer, finally, a linear elastic constitutive law was implemented in ABAQUS, with $E_{a d h}=660 \mathrm{MPa}$ and $v_{a d h}=0.38$ the modulus of elasticity and Poisson ratio respectively (Nhamoinesu and Overend, 2012).

\section{Mechanical Interactions, Post-Tensioning Stage and Bending Phase}

A key role was assigned to the mechanical interactions between the FE numerical model components, so that the post-tensioning stage alone and its effects on the post-tensioned composite assembly could be properly described.

The typical simulation consisted, consequently, in a combination of three subsequent steps carried out both in ABAQUS/Standard and ABAQUS/Explicit and namely represented by (I) pre-stressing of the CFRP tendon alone, (II) tendon release and bonding phase (III) and bending test.
Through the full FE simulation approach, a fully rigid connection was taken into account at the interface between the glass layers and the interposed SG foils, as well as at the interface between the laminated glass beam (bottom face) and the adhesive joint (top face). Any possible delamination was thus fully disregarded. For each specific stage of the FE numerical analysis, an appropriate combination of mechanical interactions, imposed loads/displacements and assigned boundary conditions was then also taken into account.

First, phase I, the post-tensioning phase was numerically reproduced in the form of a static incremental analysis. At this stage, the average experimental value of the imposed pre-stressing force $P_{0}$ was assigned to the CFRP tendon only, by means of an imposed equivalent longitudinal displacement ( $x$ direction, in accordance with the reference system of Fig. 7). During this step, no mechanical interaction was considered between the CFRP tendon and the upper beam components (i.e. the rigidly constrained adhesive layer and the laminated glass beam), being the CFRP tendon able to slide freely along the adhesive bottom surface. Since the pre-stressing force $P_{0}$ was numerically described in the form of an imposed equivalent longitudinal deformation for the tendon, the initial length of the CFRP profile itself as well as the corresponding mesh scheme was also properly defined and modified-compared to the nominal span $\mathrm{L}$ of the specimen-in order to provide an appropriate match with the upper adhesive layer mesh at the end of the prestressing procedure.

Once attained the desired level of initial prestress in the CFRP tendon alone, the release \& adhesive bonding stage was reproduced in the form of a second static incremental step (phase II). In doing so, simply support restraints were assigned at the CFRP tendon ends, in accordance with the test setup proposed in Fig. 3. A mechanical surface-to-surface interaction was then imposed at the interface between the CFRP tendon (top surface) and the adhesive layer (bottom face). As in the case of the glass-to-SG and laminated glass-to-adhesive surface interactions previously described, a fully rigid connection was taken into account (i.e. null relative displacements and rotations among the interested mesh nodes), so that the CFRP tendon release could exhibit its effects in the form of an imposed upward bending for the laminated glass beam (with $\approx 0.7 \mathrm{~mm}$ the maximum amplitude of vertical displacements observed in the current FE numerical study) and a corresponding bi-triangular distribution of initial stresses in the glass layers (see Fig. 8).

Finally, the four-point bending test simulation was carried out on the so assembled and post-tensioned reinforced assembly (phase III). At this stage, following the phase II of analysis, the adhesively bonded CFRP tendon was again simply supported at the ends, in accordance with the experimental setup provided in Fig. 3. 


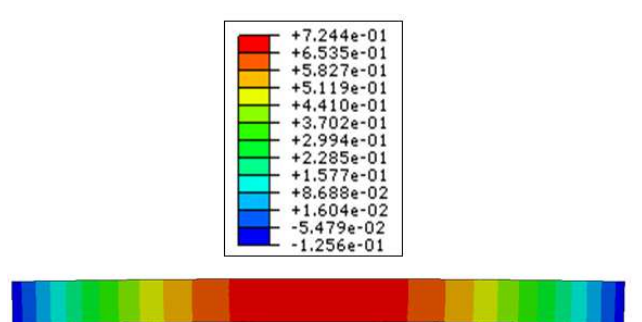

(a)

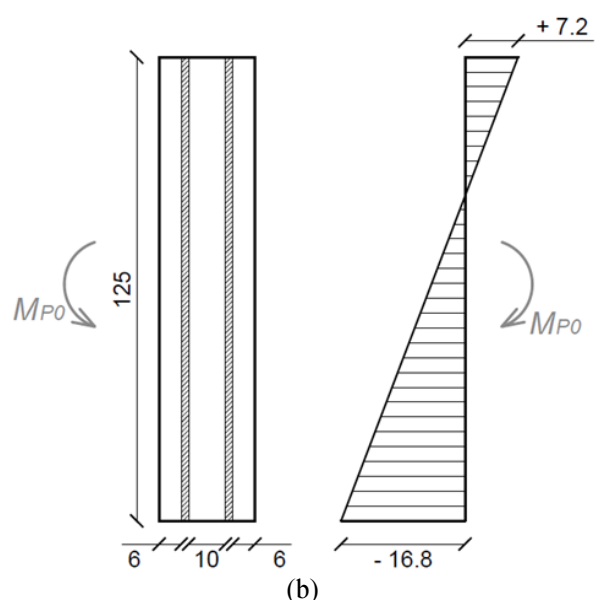

(b)

Fig. 8. Post-tensioning effect in the laminated glass beam, as numerically predicted (ABAQUS (Simulia 2012)). (a) Beam deformed shape, front view (scale factor $=5$ ) and $(b)$ corresponding distribution of initial stresses in glass (midspan transversal cross-section). Values of (a) deflections and (b) stresses given in $\mathrm{mm}$ and MPa respectively

Table 3. Experimental and FE numerical (ABAQUS (Simulia 2012)) comparisons for the bending performance of the examined CFRP-reinforced laminated glass beams

\begin{tabular}{lllll}
\hline Symbol & Unit & Test (mean) & FE & FE/Test \\
\hline $\mathrm{F}_{\text {crack }}$ & $\mathrm{kN}$ & 16.50 & 16.58 & 1.004 \\
$\mathrm{u}_{\text {crack }}$ & $\mathrm{mm}$ & 3.30 & 2.95 & 0.842 \\
$\mathrm{~K}_{\text {el }}$ & $\mathrm{kN} / \mathrm{mm}$ & 5.08 & 5.55 & 1.092 \\
$\mathrm{~K}_{\text {crack }}$ & $\mathrm{kN} / \mathrm{mm}$ & 1.56 & 1.32 & 0.846 \\
\hline
\end{tabular}

Lateral bracings able to prevent any out-of-plane deformation of the laminated glass beam were also taken into account, in the form of nodal restraints.

Nodal vertical displacements were finally assigned at the top edge of the glass layers, in order to reproduce the effect of the assigned loads during the four-point bending test, see Fig. 4. A displacement-controlled simulation was in fact carried out for the phase III, by continuously monitoring the maximum mid-span deflection of the post-tensioned system, as well as the maximum reaction forces at the beam supports, the distribution of stresses in the FE model components and the possible propagation of damage in glass. The so defined vertical displacements were linearly increased up to failure of the model, i.e. being this latter condition detected as the earliest between a possible marked drop of residual force in the fully assembled FE model, or the attainment of the ultimate vertical deflection of the experimental specimens $(\approx 25 \mathrm{~mm})$.

\section{Preliminary FE Numerical Results}

A first validation of the FE model was carried out by comparing the experimentally and numerically derived load vs. mid-span vertical deflection curves. As shown in Fig. 9 and Table 3, an interesting correlation was found between the collected results, both in terms of initial elastic stiffness and overall post-cracked performance.

The overall FE response of the beam was found to be associated to four specific phases, i.e. labeled as A, B, C and $\mathrm{D}$ in Fig. 9. The first stage of the beam bending response, up to point $\mathrm{A}$, was governed by the linear elastic stiffness of the fully collaborating, composite post-tensioned section. As far as the imposed vertical displacements representative of the experimental bending loads provided a maximum tensile stress at the bottom edge of glass able to exceed the nominal resistance of the material $f_{t}$, from Fig. 9 it can be seen that the load-deflection curve exhibits an abrupt jump and a marked variation of slope, compared to the uncracked stage, see point A. Following the first cracking occurrence, the opening of a large number of small cracks in glass-mainly located in the central part of the beam- further propagates (point B, Fig. 9). The subsequent occurrence of some major cracks towards the beam ends manifest in the form of a partial numerical instability for the so predicted load-deflection relationship, i.e. due to consistent release of damage energy (see point C, Fig. 9). The reinforced glass beam proved in any case to be still able to provide further residual resistance, with almost constant post-cracked stiffness, up to the expected experimental failure deflection (point D, Fig. 9). The FE simulation was in fact stopped at the attainment of a maximum vertical deflection of $\approx 25 \mathrm{~mm}$, being representative of the ultimate experimental deflection for the examined specimens.

First cracking in the FE model occurred at the bottom edge of glass, close to mid-span, at a vertical deflection of $\approx 2.95 \mathrm{~mm}$ and an assigned load of $\approx 16.58 \mathrm{kN}$. A rather interesting agreement with the corresponding experimental fracture deflection and reaction force was hence noticed and the FE model proved also to be able to capture the marked drop of load at the first glass cracking, as experimentally observed.

In terms of overall bending performance of the examined beam typology, both the uncracked and the post-cracked bending stiffnesses of the reinforced laminated glass beam were also properly captured by the FE model, see Fig. 9 and Table 3 ( $K_{e l}$ and $K_{\text {crack }}$ values, as derived from the slope of the experimental and numerical load-deflection curves), hence suggesting the accuracy of the mechanical and geometrical calibration process. 


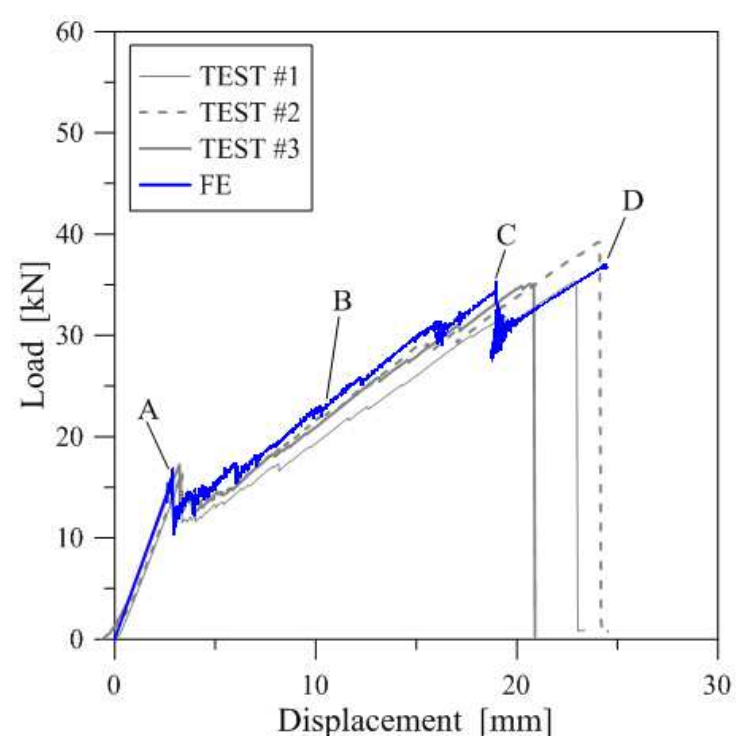

Fig. 9. Load-displacement relationship for the CFRPreinforced, post-tensioned laminated glass beams, as obtained experimentally and numerically (ABAQUS (Simulia 2012))
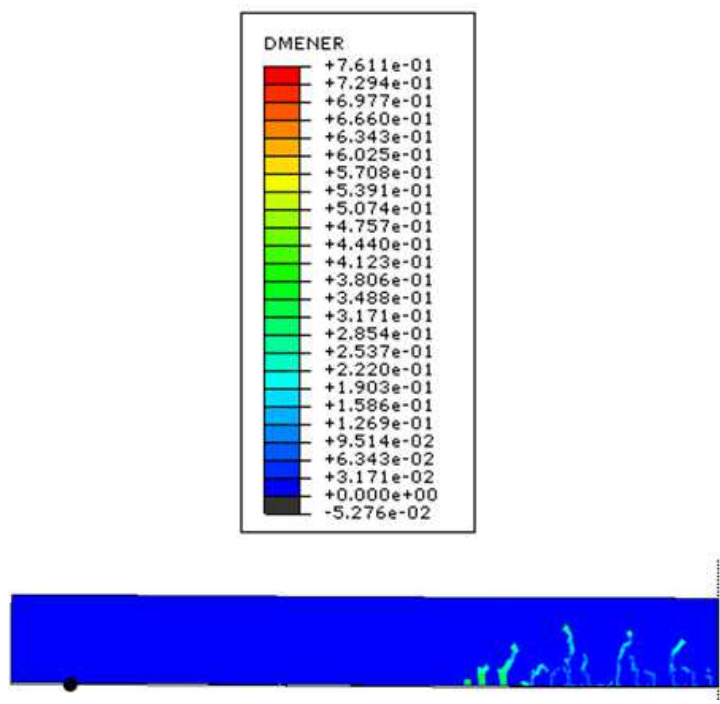

Fig. 10. Crack propagation in glass, as observed at a maximum deflection of $5 \mathrm{~mm}$ (scale factor $=1$ ), front view of half FE numerical model only (ABAQUS (Simulia 2012))

Careful consideration was then given to the distribution and propagation of cracks in glass, as well as to the amount of maximum stresses in all the FE model components. Figs. 10, 11 and 12 show respectively the observed crack pattern at a vertical deflection of $5 \mathrm{~mm}, 15 \mathrm{~mm}$ and $25 \mathrm{~mm}$ respectively. In Fig. 13, conversely, the progressive crack propagation is proposed at the same deflection amplitudes in the form of axonometric isocurves, so that the failure in the three separate glass layers could be emphasized.

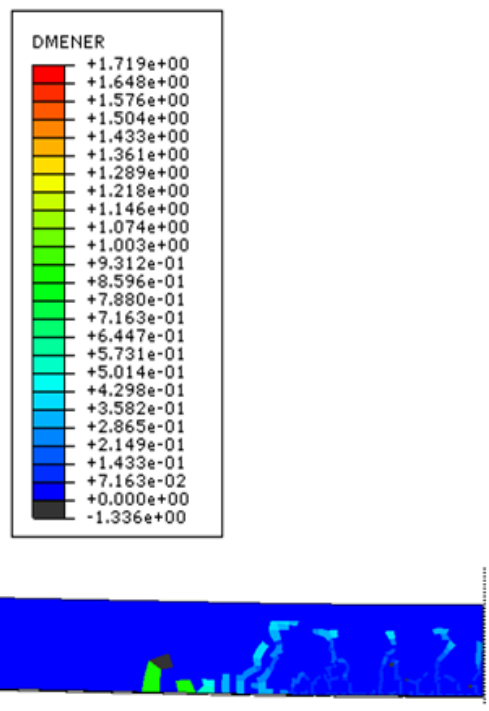

Fig. 11. Crack propagation in glass, as observed at a maximum deflection of $15 \mathrm{~mm}$ (scale factor $=1$ ), front view of half FE numerical model only (ABAQUS (Simulia 2012))
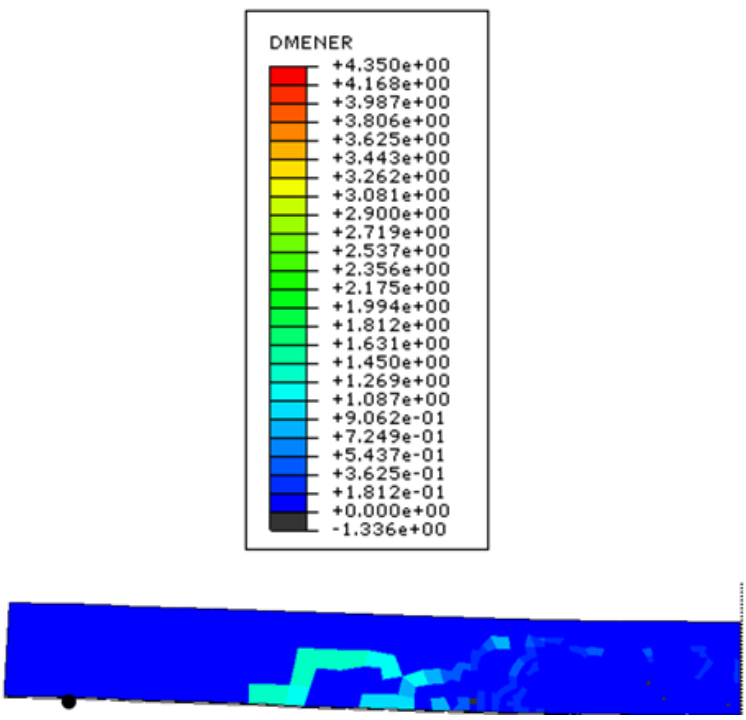

Fig. 12. Crack propagation in glass, as observed at a maximum deflection of $25 \mathrm{~mm}$ (scale factor $=1$ ), front view of half $\mathrm{FE}$ numerical model only (ABAQUS (Simulia 2012))

As shown, glass cracks mainly interested a large region of the beam bottom edge, as also observed experimentally. At the vertical deflections of $15 \mathrm{~mm}$ and $25 \mathrm{~mm}$, it is also possible to distinguish few major cracks opening towards the beams ends.

In accordance with past research projects (see for example Louter and Nielsen, 2013; Bedon and Louter, 2014; Bedon and Louter, 2016), in addition, an almost uniform propagation of cracks through the beam thickness was generally observed, as also highlighted by the axonometric isocurves proposed in Fig. 14. 


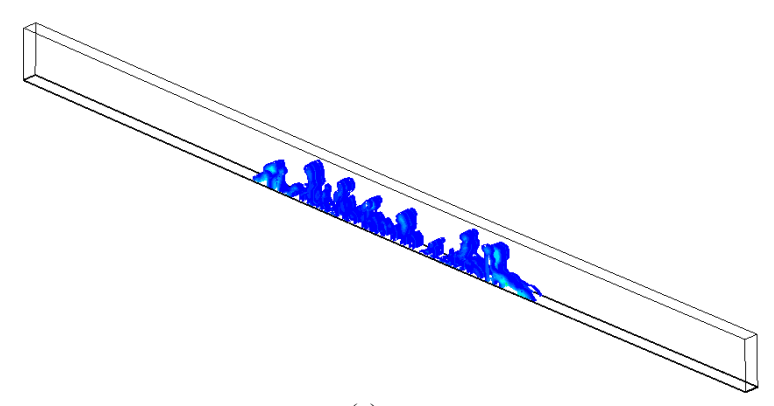

(a)

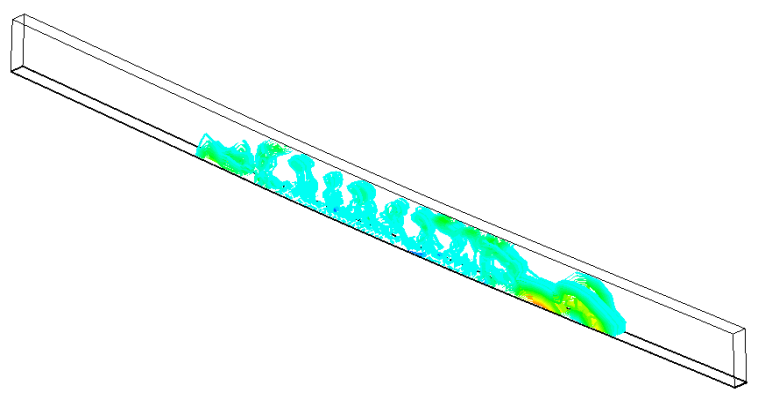

(b)

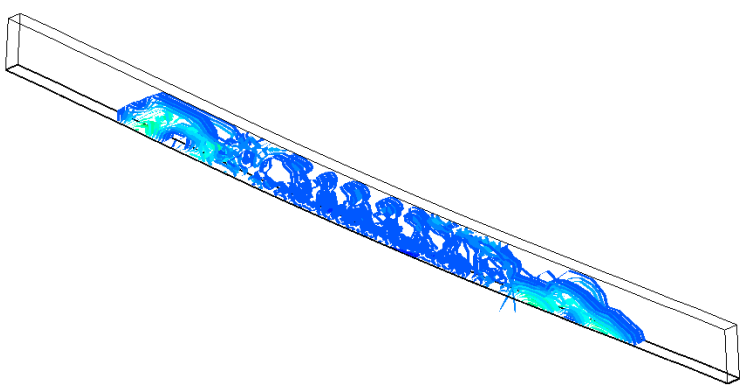

(c)

Fig. 13. Crack propagation in glass, axonometric isocurves at selected deflection amplitudes for the FE numerical model (ABAQUS (Simulia 2012)) (a) $\mu_{\max }=5 \mathrm{~mm}$; $\mu_{\max }=15 \mathrm{~mm}$; (c) $\mu_{\max }=25 \mathrm{~mm}$

In terms of stress distribution in the main FE model components, the compressive stress at the glass top edge was first monitored. As far as the brittle cracking option provides in fact a valid tool for the tensile cracking simulation of brittle elastic materials, the limit of the same approach is that the compressive resistance is considered as unlimited through the full simulation.

The typical distribution of compressive stresses in glass is proposed in Figs. 14a-c, at a deflection amplitude of $5 \mathrm{~mm}, 15 \mathrm{~mm}$ and $25 \mathrm{~mm}$ respectively. In the figure, half glass beam is only proposed, taking advantage of symmetry (with the adhesive layer and the CFRP tendon hidden from the view). As shown, major peaks of compressive stresses in glass are mainly located in the vicinity of cracks as well as at the top edge of the laminated glass beam.
The collapse configuration for the experimental test specimens, see Fig. 14c, is associated to a numerically predicted maximum compressive stress at the top edge of glass in the order of $\approx 290 \mathrm{MPa}$.

In Fig. 15a, the corresponding envelope of maximum compressive stresses at the top edge of the glass beam is also shown, as a function of the monitored beam midspan deflection. There, the experimentally observed range of deflections at collapse for the test specimens is emphasized. The maximum compressive stress value in glass was found to be typically lower than the corresponding nominal resistance of the material, namely in the order of $1000 \mathrm{MPa}$, as well as in agreement with other numerical research investigation on similar structural glass beams (see for example Bedon and Louter, 2016).

Regarding the CFRP tendon, the maximum stress recorded at a deflection of $\approx 25 \mathrm{~mm}$ resulted equal to $\approx 1500 \mathrm{MPa}$ (see Fig. 15(b)), corresponding to a maximum strain in the order of $\approx 0.8 \%$. In this sense, the observed maximum tensile stress value and strain resulted markedly lower than the nominal strength and elongation at rupture provided by the producer (i.e. $2550 \mathrm{MPa}$ and $1.7 \%$ respectively, see Table 1 ).

It should be noticed, in this context, that the one of the examined experimental prototypes manifested at failure a full debonding of the CFRP tendon profile from the laminated glass beam and the currently implemented FE numerical model is not able to capture this specific typology of collapse mechanism. A further attempt was in any case carried out, in order to find a possible correlation between the experimental failure mechanism and the corresponding FE numerical simulation.

Figure $15 \mathrm{c}$, in this regard, presents the evolution of maximum shear stresses at the interface between the adhesive layer and the CFRP/laminated glass beam, in the form of maximum envelope as a function of the beam mid-span deflection. The so obtained stress values are compared with the nominal resisting shear stress of 36.1MPa provided by the producer (3M Scotch-Weld ${ }^{\mathrm{TM}}$, 1996) for the adopted adhesive, in the case the adherend consists of carbon fiber reinforced epoxy components. From (Belis et al., 2011), a reference shear strength of 28.75MPa for glass-to-aluminum adhesive connections was also taken into account.

As shown, the variation of the collected FE shear stresses is affected by propagation of cracks in glass, through the full analysis. At the expected collapse deflection for the examined test specimens, in particular, the FE maximum shear stresses in the adhesive were found to be comprised in the range of $\approx 45-50 \mathrm{MPa}$. Compared to the CFRP tendon and the glass layers, where the compressive and tensile maximum stresses were found to be low compared to the reference failure values, the adhesive layer resulted a crucial component for the examined beams. 


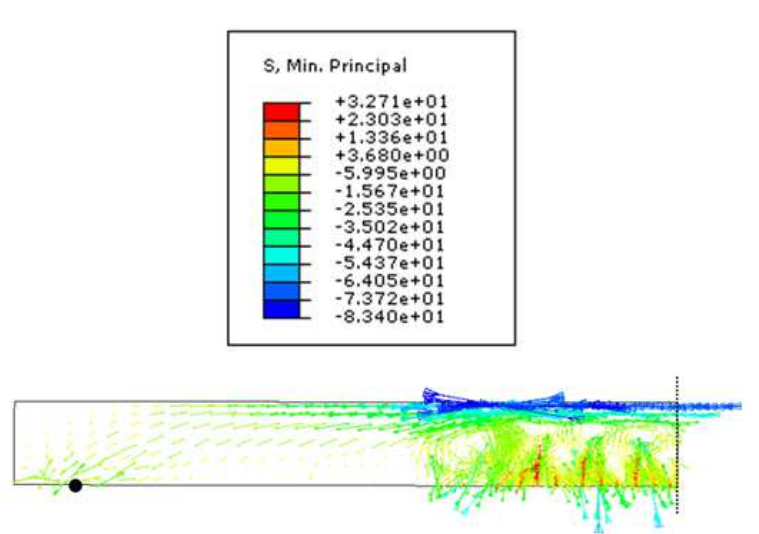

(a)

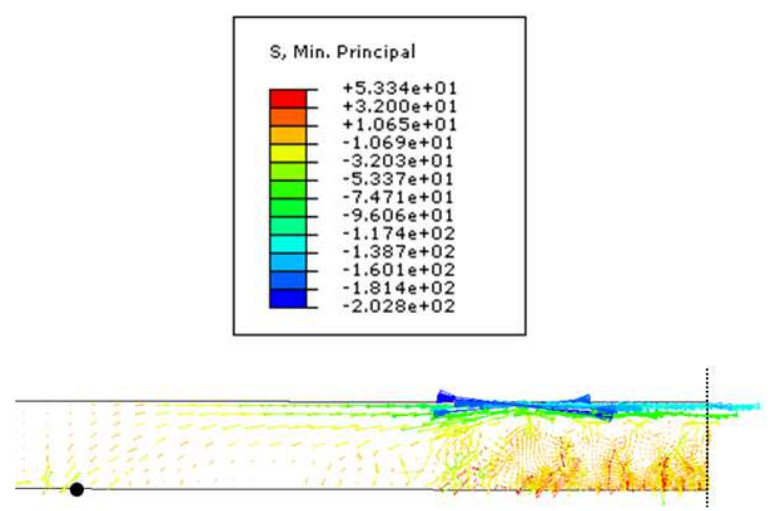

(b)

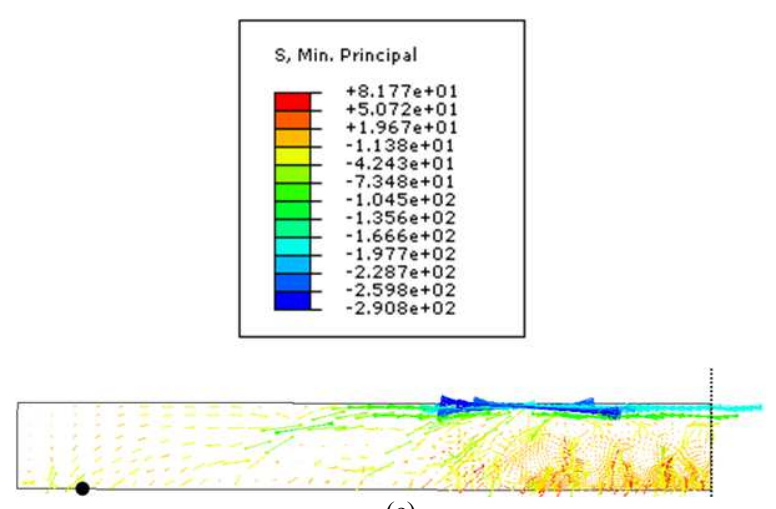

(c)

Fig. 14. Distribution of compressive stresses in the glass beam, front view (vectorial representation) of half $\mathrm{FE}$ numerical model only, at selected deflection amplitudes (scale factor $=1$; ABAQUS (Simulia 2012)). Values of stresses given in MPa; (a) $\mu_{\max }=$ $5 \mathrm{~mm} ; \mu_{\max }=15 \mathrm{~mm}$; (c) $\mu_{\max }=25 \mathrm{~mm}$

Due to the basic assumptions of the proposed FE model, however, further extended investigations at the assembly as well as at the material/component level are still required.

In this sense, the current FE investigations and outcomes proved to provide an interesting correlation with the available experimental results.

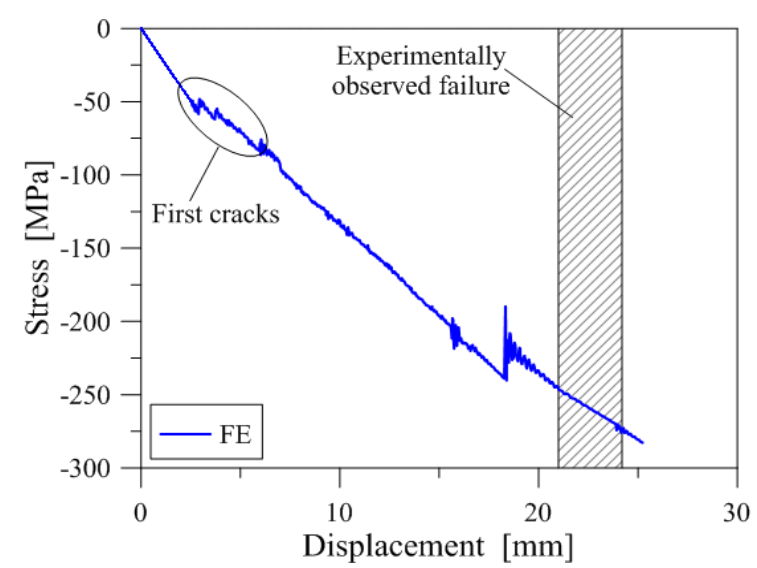

(a)

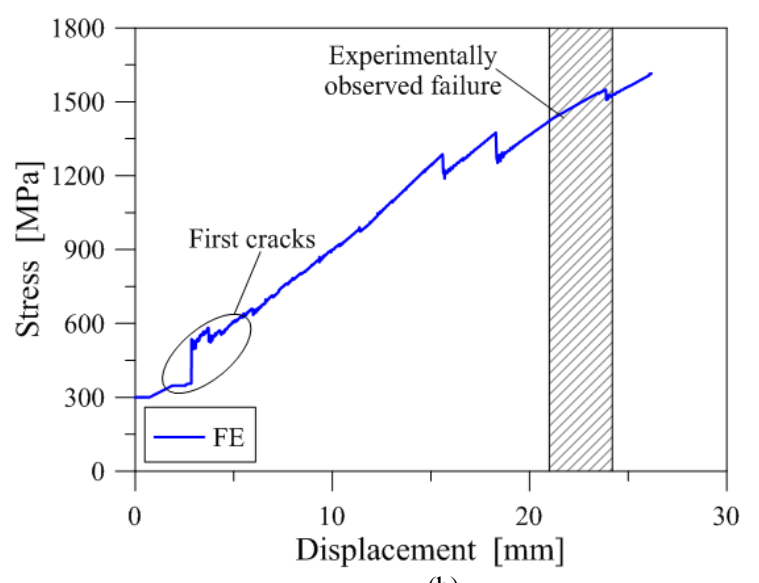

(b)

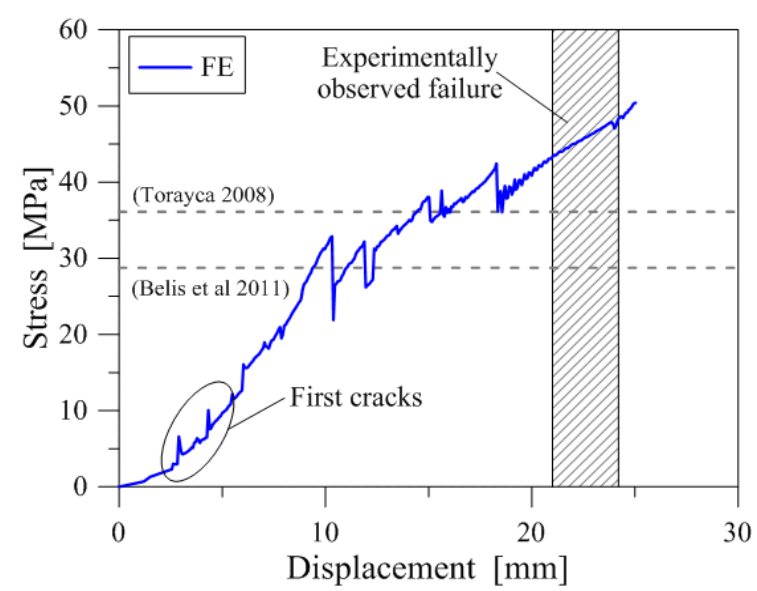

(c)

Fig. 15. Evolution (maximum envelope) of (a) compressive stresses at the top edge of glass; (b) tensile stresses in the CFRP tendon and (c) shear stresses on the adhesive layer faces, as a function of the beam midspan deflection, as obtained from the FE

It is this expected that the further extension of the research investigation could allow to fully assess the FE modeling calibration (i.e., to capture the actual collapse 
mechanisms of the test prototypes, including for example delamination phenomena) as well as to further explore the design concept of CFRP-reinforced and post-tensioned laminated glass beams.

\section{Conclusion}

In this study, the potential of a structural glass beam concept of post-tensioned glass beams with adhesively bonded CFRP tendons has been explored by means of a refined Finite-Element (FE) numerical model. Taking advantage of past experimental test results available for the same beam typologies, a refined calibration and validation of the reference full 3D FE model is first proposed.

As shown, a key role was assigned to a multitude of aspects, including advanced damage models (i.e. for the tensile cracking of glass) as well as a combination of mechanical interactions and imposed loads/displacements through the full FE numerical simulation. The final result, as critically discussed in the paper, is a refined FE model able to properly capture the effects due to the assigned pre-stressing force, as well as the overall bending performance of the so assembled and reinforced CFRP-laminated glass beam.

It is expected, based on the current outcomes, that the presented FE modeling approach and results could be further extended to fully assess and optimize the examined design concept.

\section{Acknowledgement}

MSc student Mathieu Débonnaire (École Polytechnique Fédérale de Lausanne (EPFL), Lausanne, Switzerland) who has performed the experiments during his MSc thesis project at EPFL is gratefully acknowledged for his work.

\section{Author's Contributions}

Both the authors actively contributed to the preparation and drafting of the paper, including elaboration of experimental results; Finite-Element numerical modeling calibration and validation of the working assumptions; critical discussion of the FE numerical results and comparative studies.

\section{Ethics}

The article is original and contains, apart from the summarized earlier experimental results, unpublished material only. The corresponding author confirms that both the authors have read and approved the manuscript and no ethical issues are involved.

\section{References}

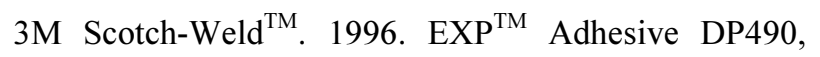
Product Data Sheet.
Bedon, C. and C. Louter, 2014. Exploratory numerical analysis of SG-laminated reinforced glass beam experiments. Eng. Structures, 75: 457-468. DOI: $10.1016 /$ j.engstruct.2014.06.022

Bedon, C. and C. Louter, 2016. Finite-Element analysis of post-tensioned SG-laminated glass beams with mechanically anchored tendons. Glass Structures Eng., 1: 1-39. DOI: 10.1007/s40940-016-0020-7

Belis, J., A. Van Hulle, B. Out, F. Bos and D. Callewaert et al., 2011. Broad screening of adhesives for glass-metal bonds. Glass Performance Days.

Bos, F., F. Veer, G. Hobbelman and C. Louter, 2004. Stainless steel reinforced and post-tensioned glass beams. Proceedings of 12th International Conference on Experimental Mechanics, 29 Aug. -2 Sept., Politecnico di Bari, Italy, pp: 1-9.

Colombi, P. and A. Poggi, 2006. An experimental, analytical and numerical study of the static behavior of steel beams reinforced by pultruded CFRP strips. Coposites Part B: Eng., 37: 64-73. DOI: 10.1016/j.compositesb.2005.03.002

Correia, J.R., L. Valarinho and F.A. Branco, 2011. Post-cracking strength and ductility of glass-GFRP composite beams. Composite Structures, 93: 22992309. DOI: 10.1016/j.compstruct.2011.03.018

Cupać, J. and C. Louter, 2015. Post-tensioned Structural Glass Beams-Comparative Experimental Study. Proceedings of the Advanced Building Skins, April 23-24, EPFL, Graz pp: 165-172.

Débonnaire, M., 2013. Post-tensioned glass beams. MSc Thesis. EPFL, Lausanne, Switzerland.

EN 572-2:2004. Glass in buildings-Basic soda lime silicate glass products. CEN, Brussels, Belgium.

Engelmann, M. and B. Weller, 2016. Post-tensioned glass beams for a $9 \mathrm{~m}$ Spannglass Bridge. Structural Eng. Int., 26: 103-113. DOI: $10.2749 / 101686616 \mathrm{X} 14555428759000$

Johnsson, H., T. Blanksvärd and A. Carolin, 2006. Glulam members strengthened by carbon fibre reinforcement. Materials Structures, 40: 47-56. DOI: $10.1617 / \mathrm{s} 11527-006-9119-7$

Jordão, S., M. Pinho, J.P. Martins, A. Santiago and L.C. Neves, 2014. Behaviour of laminated glass beams reinforced with pre-stressed cables. Steel Construction, 7: 204-207. DOI: $10.1002 /$ stco. 201410027

Khalifa, A. and A. Nanni, 2002. Rehabilitation of rectangular simply supported RC beams with shear deficiencies using CFRP composites. Construction Building Materials, 16: 135-146. DOI: $10.1016 / \mathrm{S} 0950-0618(02) 00002-8$

Louter, C. and J.H. Nielsen, 2013. Numerical analyses of the effect of SG-interlayer shear stiffness on the structural performance of reinforced glass beams. Proceedings of the COST Action TU0905 Mid-term Conference On Structural glass, pp: 405-11. 
Louter, C., J. Cupać and J.P Lebet, 2014b. Exploratory experimental investigations on post-tensioned structural glass beams. J. Facade Design Eng., 2: 3-18. DOI: $10.3233 /$ FDE-130012

Louter, C., J. Cupać and M. Débonnaire, 2014a. Structural glass beams prestressed by externally bonded tendons. Proceedings of GlassCon Global Conference, July 7-10, Philadelphia, PA, USA.

Martens, K., R. Caspeele and J. Belis, 2015a. Development of composite glass beams: A review. Eng. Structures, 101: 1-15.

DOI: $10.1016 /$ j.engstruct.2015.07.006

Martens, K., R. Caspeele and J. Belis, 2015b. Development of reinforced and posttensioned glass beams: Review of experimental research. ASCE J. Structural Eng. DOI: 10.1061/(ASCE)ST.1943-541X.0001453

Nadira, Y., P. Nagarajan, M. Ameen and M. Arif, 2016. Flexural stiffness and strength enhancement of horizontally glued laminated wood beams with GFRP and CFRP composite sheets. Construction Building Materials, 112: 547-555.

DOI: 10.1016/j.conbuildmat.2016.02.133

Nhamoinesu, S. and M. Overend, 2012. The mechanical performance of adhesives for a steel-glass composite façade system. Proceedings of Challenging Glass 3-Conference on Architectural and Structural Applications of Glass, TU Delft.
Santarsiero, M., C. Louter and A. Nussbaumer, 2016. The mechanical behaviour of SentryGlas $\backslash(\wedge\{\mid$ circledR $\} \backslash)$ ionomer and TSSA silicon bulk materials at different temperatures and strain rates under uniaxial tensile stress state. Glass Structures Eng. DOI: 10.1007/s40940-016-0018-1

Schober, H., H. Gerber and J. Schneider, 2004. Ein Glashaus für die Therme in Badenweiler. Stahlbau, 73: 886-892. DOI: 10.1002/stab.200490213

Seleem, M.H., I.A. Sharaky and H.E.M. Sallam, 2010. Flexural behavior of steel beams strengthened by carbon fiber reinforced polymer plates-Three dimensional finite element simulation. Materials Design, 31: 1317-1324.

DOI: $10.1016 /$ j.matdes.2009.09.010

Simulia, 2012. ABAQUS v.6.12 computer software and online documentation, dassault systems. Providence, RI, USA.

Speranzini, E. and S. Agnetti, 2015. Flexural performance of hybrid beams made of glass and pultruded GFRP. Construction Building Materials, 94: 249-262.

DOI: 10.1016/j.conbuildmat.2015.06.008

Torayca, 2008. T700 Technical Data Sheet No. CFA005.

Wu, Z., L. Wenxiao and N. Sakuma, 2005. Innovative externally bonded FRP/Concrete hybrid flexural members. Composites Structures, 72: 289-300. DOI: $10.1016 /$ j.compstruct.2004.12.002 